\title{
WHY THE INDIFFERENCE OF THE UNIVERSE IS IRRELEVANT TO LIFE'S MEANING
}

\author{
BROOKE ALAN TRISEL
}

\begin{abstract}
When pessimists claim that human life is meaningless, they often also assert that the universe is "blind to good and evil" and "indifferent to us". How, if it all, is the indifference of the universe relevant to whether life is meaningful? To answer this question, and to know whether we should be concerned that the universe is indifferent, we need a clearer and deeper understanding of the concept of "cosmic indifference", which I will seek to provide. I will argue that the lives of many individuals are meaningful and that human life, in general, is somewhat meaningful, despite the indifference of the universe. Furthermore, I will seek to demonstrate that even if the universe cared about us, or had preferences for how we live our lives, that this likely would not enhance the quality of our lives.
\end{abstract}

Key words: Indifferent universe; existentialism; Albert Camus; meaning of life

\section{Introduction}

The notion that the universe is "indifferent to us" permeates the writings of pessimists and existentialists and led many of them to express feelings of disappointment and despair about our existence. Many of these thinkers claim that human life is meaningless from the vast, cosmic perspective. When making this claim, they often also assert that the universe is indifferent to us. For example, David Benatar (2017, p. 2) writes: "We are insignificant specks in a vast universe that is utterly indifferent to us".

Bertrand Russell (2000, p. 77) also expressed the concern that the universe is indifferent, when he wrote: "Blind to good and evil, reckless of destruction, omnipotent matter rolls on its relentless way ...". In an indifferent universe, we could make a great collective achievement and the universe will not praise the achievement or even be aware that it occurred. Moreover, human beings could bring about the annihilation of all sentient life on Earth, through global warming or nuclear war, and the 
universe would not shed a tear. Thus, the universe does not have a preference as to whether we flourish or perish.

Albert Camus famously declared that human life is absurd. By "absurd”, Camus (1955, p. 28) meant that there is a clash between human desires for happiness, meaning, justice, and reason and the "unreasonable silence" of the universe to our desires. Absurdity "is that divorce between the mind that desires and the world that disappoints ...", Camus (1955, p. 50) writes. When describing the universe, Camus often uses the word "silence" instead of "indifference". His philosophic writings are notoriously obscure and his discussion of "silence" is no exception.

Should we be concerned that the universe is indifferent? Is the indifference of the universe relevant to whether life is meaningful? To answer these questions, we need a clearer and deeper understanding of the concept of "cosmic indifference", which I will seek to provide in section two. In section three, I will argue that the lives of many individuals are meaningful and that human life, in general, is somewhat meaningful, despite the indifference of the universe. In section four, I will seek to demonstrate that even if the universe cared about us, or had preferences for how we live our lives, that this likely would not enhance the quality of our lives.

\section{The meanings of "cosmic indifference"}

The word "indifference" has two meanings that are relevant to this analysis. ${ }^{1}$ First, indifference can mean a general lack of concern as, for example, if someone said, "Most people are indifferent to the children starving in Ethiopia”. Second, indifference can mean lacking a preference for one alternative over another.

Although there has been very little philosophic analysis of the notion of "cosmic indifference", the concept of "preference", which has a meaning opposite of "indifference", has played a central role

\footnotetext{
${ }^{1}$ See Lillehammer (2017) for more discussion about the meanings of "indifference".
} 
in moral philosophy, decision theory, and modern economics. ${ }^{2}$ Preferences are comparative in that they involve an evaluation of two or more alternatives. For example, you may prefer strawberry ice cream over vanilla or vice versa. If a person is indifferent to the alternatives under consideration, then this person values the alternatives equally and thus has no preference.

The first meaning of cosmic indifference is that the universe has a general lack of concern "for us", as, for example, when Camus indicates that the universe is silent to our desires. In contrast, the second and narrower meaning of cosmic indifference is that the universe lacks preferences for "what we should do" in our lives. Russell employs this sense of "indifference" when he asserts that the universe is blind to the alternatives of good and evil. Camus also uses "indifference" in this second sense. For example, in commenting on the famous phrase "everything is permitted"3 in the absence of God, he writes: "if all experiences are indifferent, that of duty is as legitimate as any other" (Camus, 1955, p. 67).

When people claim that the universe is indifferent to us, they often forget that we are a part of the universe. Thus, one might try to argue that the universe cannot be indifferent to us because we are part of the universe. However, in response, pessimists will distinguish between human beings and the "rest of the universe", and will point out that this argument does nothing to alleviate their concern that the "rest of the universe" is indifferent to us.

I concede that the rest of the universe is indifferent to us. Some people express feelings of disappointment, anger, alienation, and despair in response to the indifference of the universe. Are they wise to do so? To know how we should feel about the indifference of the universe, we first need to reflect on why the universe is indifferent. To use an analogy, suppose Mary angrily shouts, "Joan has been indifferent to me lately". Mary seeks your advice on how to deal with this situation.

\footnotetext{
${ }^{2}$ See Hansson \& Grüne-Yanoff (2018).

${ }^{3}$ These words appear in Dostoevsky's novel The Brothers Karamazov. For more discussion, see Wielenberg (2005, pp. $11,53-65,113-114)$
} 
A person might be "indifferent" to another person for many different reasons. Therefore, before providing any advice to Mary, a wise person would first seek to understand why Joan has been indifferent to Mary.

Suppose that you learn that Joan was in a car accident, which left her comatose and incapable of responding to Mary. In this example, it is clear that Mary's anger towards Joan for being indifferent is inappropriate. Similarly, feeling disappointment or anger at the universe for being indifferent to us is inappropriate. If the universe had the capability to care about us, but chose not to, then one might be justified in being angry about this. However, the reason the universe is indifferent to us is because it is non-sentient and incapable of caring about anything or having preferences. Fortunately, the lives of many people are meaningful, and humanity is somewhat meaningful, despite the indifference of the universe, as I will argue in the next section.

\section{Attaining meaning despite the indifference of the universe}

Supporters of "objective naturalism", including myself, believe that meaning is attained in our lives by engaging with natural, mind-independent, and intrinsically valuable goods. ${ }^{4}$ Benatar acknowledges that one's individual life can be objectively meaningful, from human-based perspectives, by transcending one's limits and making a difference to another person or a group of people. However, he contends that human beings do not make a difference to the rest of the cosmos beyond Earth. For this reason, he concludes that our individual lives, and human life, in general, are meaningless from the vast, "cosmic perspective". The cosmic perspective is sometimes also called the "view from everywhere". It is the view we imagine an impartial observer would have if this observer could witness the entire universe unfold over time.

In reflecting on the death of God and the indifference of the universe, Camus (1955, p. 6)

\footnotetext{
${ }^{4}$ For more discussion, see Metz (2013, pp. 180-239) and Landau (2017).
} 
writes: "in a universe suddenly divested of illusions and lights, man feels an alien, a stranger". Although the universe lacks the capabilities to care about us and to have preferences, it has many other, and more important, capabilities that provide a context in which many people are happy and lead meaningful lives. First, the universe gave rise to life that evolved into Homo sapiens. Second, the universe unknowingly provides us with resources that sustain and nourish our existence, including food, water, shelter, and sunlight. Third, the universe provides continuity, order, and law-like predictability, such that we can envision goals in the future and work toward achieving these goals. Fourth, the universe contains intrinsically valuable goods such as knowledge, loving relationships, autonomy, and achievements. Pursuing and promoting these and other objective goods adds meaning to our lives and does so despite the indifference of the universe. By considering the above-mentioned capabilities of the universe, one feels, not as a stranger, but "at home" in the universe.

Our living quarters, where we eat and sleep, are indifferent to us and this does not concern us at all. Similarly, it need not concern us if our larger home - the universe - is incapable of caring about us or having preferences for how we live our lives.

By acknowledging that the lives of many people are meaningful from human-based perspectives, Benatar unintentionally helps to demonstrate that whether the universe cares about us, or has preferences, is unnecessary for our individual lives to be meaningful from human-based perspectives. Benatar might try to argue that whether the universe cares about us or has preferences is somehow relevant to whether human life, in general, is meaningful from the cosmic perspective, but he would need to say more about this because its relevance is unclear.

Whether human life was created for a purpose by the universe is relevant to whether human life is meaningful. However, whether the universe created human life for a purpose, and whether the universe cares about us, are two different capabilities and are not necessarily related. For example, the universe could have created human life for a purpose, such as for us to serve as a source of 
entertainment, but it might not care about us. Alternatively, the universe could care about us without having created human life for a purpose.

Although it is highly doubtful that human life was created for a purpose by the universe or a god, individual human beings have self-chosen purposes and collectively make up "humanity". As we add meaning to our individual lives through relationships, projects, and achievements, this would also add meaning to humanity if meaning aggregates across human beings.

In the 13.772-billion-year-history of the universe, Homo sapiens emerged very recently, around 200,000 years ago. Thus, the "perspective of humanity", as Benatar calls it, is much narrower than the cosmic perspective. As I have argued elsewhere, ${ }^{5}$ in our quest to understand the universe, human beings have transcended the narrow perspective of humanity and made some difficult to make and valuable achievements, which has given human life some meaning from the cosmic perspective. Some examples of these "transcending achievements", as I call them, include formulating the laws of motion, the theory of relativity, and the Big Bang theory of the origin of the universe.

To summarize this section, feeling disappointed or angry at the universe for being indifferent is unjustified and unwise. The lives of many individuals are meaningful, despite the indifference of the universe. Furthermore, humanity stands out and matters from the cosmic perspective by having made some remarkable, transcending achievements, and we did not need the universe to care about us or to have preferences for this to occur.

To his credit, Benatar reflects on why the universe is indifferent to us - because it lacks the capability to care about us or, in his words, because it "has no attitudes at all" (Benatar, 2017, p. 200). Thus, Benatar will likely concede that we are unjustified in feeling angry at the universe for being indifferent to us. However, he may then respond that we are justified in feeling disappointed that we exist in a universe that lacks the capabilities to care about us and provide us with moral guidance. This

\footnotetext{
${ }^{5}$ Trisel (2019).
} 
argument, however, is based on the assumption that the quality of our lives would be better if the universe cared about us or had preferences. In the next section, I will seek to demonstrate that this assumption is false.

\section{A thought experiment}

If the universe cared about us or had preferences for what we do in our lives, would that enhance the quality of our lives, in terms of making them more meaningful or happy? ${ }^{6}$ We will engage in a thought experiment to answer this question. Whether the universe cares about us or has preferences are two distinct capabilities that are not necessarily related. For example, the universe might care about us, but lack the ability to have preferences. Because these capabilities are distinct, I will analyze them separately in the following thought experiment.

Let us begin this experiment by supposing that the universe cares about us, but that it lacks the capability to do anything about what we experience in our lives, such as alleviate suffering. The capability of caring is central to the concept of "indifference", whereas the distinct capability of being powerful is not, which is why we will imagine that the universe cares about us, but is powerless to help us. We will suppose, for example, that the universe is sympathetic to us, but is unable to prevent a hurricane or relieve the suffering of hurricane victims. Would a caring universe enhance the quality of our lives?

One might think that a caring universe might motivate us. However, a caring universe would serve as a poor motivator for similar reasons to why the awareness of our mortality does not usually motivate people to make their lives more meaningful. Although we know that we will die, we do not know when we will die. As a result, one's death can seem distant and is easily put out of mind. ${ }^{7}$ If the

\footnotetext{
${ }^{6}$ For the differences between meaning and happiness, see Metz (2009).

${ }^{7}$ For more discussion, see Trisel (2015).
} 
rest of the universe beyond Earth cared about us, but was incapable of intervening in our lives, this would also seem distant. It would be "out of sight, out of mind", as the adage goes. Consequently, it would not likely motivate people to undertake new activities or projects that would add objective meaning to their lives. Granted, some people might initially have an increase in subjective happiness if they discovered that the rest of the universe cares about human beings. However, this effect would likely be temporary.

Psychologists distinguish between intrinsic and extrinsic motivation. ${ }^{8}$ A person is intrinsically motivated when he or she does something because it is inherently interesting or enjoyable. In contrast, one is extrinsically motivated when one takes action to realize an external reward or to avoid an external sanction. The awareness that we will die is an extrinsic form of motivation. Furthermore, it is a non-specific form of extrinsic motivation insofar as it provides no guidance as to what a person should do to add meaning to his or her life. Having the universe care about us would also be an extrinsic and non-specific form of motivation. If it would serve as a motivation, what would it motivate us to do? Without knowing what it would motivate us to do, it is unclear whether it would increase the meaning in our lives.

Benatar laments that the universe is indifferent to our "hopes, fears, values, and concerns" (2017, p. 13). Thus, he seems to assume that if the universe had preferences for what we do in our lives that this would somehow support our values. Is this a correct assumption? Would a universe with preferences provide us with trustworthy, moral guidance? By reflecting on the famous Euthyphro dilemma, it will reveal a concern about whether we could trust this guidance. The Euthyphro dilemma, as expressed by Plato, concerns the relationship between God and morality. However, even if God does not exist, this dilemma would arise if the universe had preferences or, in other words, was not indifferent, about how we should conduct ourselves. Before explaining this, I will provide a brief

\footnotetext{
${ }^{8}$ See Ryan \& Deci (2000).
} 
overview of the modern day, theistic version of the dilemma.

The Euthyphro dilemma is revealed in the following question: Is an action morally right because God commands it, or does God command it because it is morally right? If an action is morally right simply because God says it is right, then this provides a flimsy, arbitrary, and untrustworthy basis for morality. For example, it would raise the concern that an action that seems terrible, such as torturing an innocent child, could be right and obligatory if God commanded it. Alternatively, if our conduct is morally right or wrong independently of God, then this seems to make God superfluous to morality, especially if we are able to determine, on our own, what is right or wrong without any assistance from God. ${ }^{9}$

In a Godless world, and if the universe had preferences for what we do in our lives, we would be faced with the following, naturalistic version of the Euthyphro dilemma: Is an action morally right because the universe prefers it, or does the universe prefer it because it is morally right?

If an action is right or wrong simply because the universe prefers it, then this raises the concern of whether we can trust the preferences of the universe. The universe, for example, might prefer that we undertake an action that seems awful. One way that theists have responded to the Euthyphro dilemma is by arguing that God would never command cruelty because doing so would be inconsistent with God's perfect and loving nature. ${ }^{10}$ However, in the Godless scenario under consideration, this response will not work because the universe is imperfect.

Regarding the second scenario, if the universe prefers an action because it is morally right, then morality is grounded on something other than the preferences of the universe and thus having a universe with preferences is unnecessary. In response, one might agree with this, but then argue that it would still be beneficial for the universe to have preferences because the universe might be better able than human beings to learn what is right or wrong, which could help us if the universe shared these

\footnotetext{
${ }^{9}$ For more discussion, see Wielenberg (2005, pp. 38-67).

10 See, for example, Adams (1987, p. 102).
} 
preferences with us. But how would we know that the preferences that the universe shares with us are consistent with what grounds morality and are trustworthy?

In summary, under both scenarios - whether an action is right because the universe prefers it or is right independently of what the universe prefers - the concern arises about whether we could trust the preferences of the universe. If the universe had preferences, this would require us to go out on a limb and trust those preferences. We cannot assume that the quality of our lives would increase by following those preferences. In fact, there is a risk that the quality of our lives could decrease and that the universe could betray our trust. This could occur if the universe was incompetent, malevolent, or its preferences were arbitrary.

A universe with preferences would only be beneficial to us if those preferences were more trustworthy than our own decisions, and individuals chose to follow the guidance reflected in those preferences. But to know whether the preferences of the universe are more trustworthy than our own decisions, we would first need to discover what the universe prefers, and what, if anything, these preferences are based on. Furthermore, to determine whether following the preferences of the universe would enhance the quality of our lives, we would need to do some empirical testing and compare the amount of meaning and happiness in the lives of those individuals who follow these preferences against those who choose to disregard this guidance.

\section{Relieving existential anguish}

The universe provides a context in which many people are happy and lead meaningful lives. Rather than being grateful that we exist in such a world, some pessimists are disappointed and desire infinitely more. They want everlasting lives ${ }^{11}$ and the complete absence of suffering. ${ }^{12}$ They want for human life

\footnotetext{
${ }^{11}$ See, for example, Benatar (2017, pp. 3, 202-203).

${ }^{12}$ See, for example, Benatar (2017, p. 85).
} 
to have been created to fulfill a purpose. ${ }^{13}$ And they want the universe to support our values and to care about us.

Pessimists focus on what they think is lacking in this world and so they see the "glass" (of existence) as being half empty, whereas optimists see the glass as being half full because they appreciate the world as it is, despite its limitations and imperfections. As suggested in the prior paragraph, some pessimists have towering expectations. These expectations have been shattered twice: with the collapse of belief in God, and then through their later realization that the universe was incapable of standing in as a personal god and satisfying the desires they had expected God to fulfill. It is no wonder that some of them express disappointment and despair in their writings.

Pessimists are justifiably concerned about the amount of suffering in the world. However, they fail to recognize that some of their own suffering is self-inflicted and occurs by acquiring, and then firmly holding on to, unattainable desires. Pessimists have often looked outward to God or the universe to fulfill their towering expectations and relieve their anguish. Not surprisingly, God and the universe have been non-responsive. Fortunately, we can relieve some of our existential anguish by looking inward and letting go of the anxiety-producing desires for God or the universe to care about us, relieve suffering, and provide us with moral guidance and everlasting life.

\section{Conclusion}

One of the joys and benefits of engaging in philosophic reflection is that it can sometimes dispel a lingering concern, which I hope this paper will do. By clarifying the concept of "cosmic indifference", and then testing, in a thought experiment, whether the quality of our lives would be any better if the universe cared about us or had preferences, it has become clear that there is no justification for being

\footnotetext{
${ }^{13}$ See, for example, Benatar (2017, pp. 36, 40-41). Contrary to Sartre (2007, pp. 21, 41, 53), Benatar (p. 40) indicates that it would be "wonderful if there were a beneficent God who had created us for good reason. ..".
} 
concerned that the universe is indifferent to us.

The indifference of the universe does not prevent us from leading meaningful individual lives, as demonstrated by, for example, Albert Einstein and Nelson Mandela. Furthermore, by having made some transcending achievements, humanity stands out and matters from the cosmic perspective, despite the indifference of the universe.

Even if the universe had the capabilities to care about us or to have preferences, this likely would not enhance the quality of our lives or relieve the anguish of pessimists for the following two reasons. First, a universe that cared about us would be "out of sight, out of mind" and, consequently, would not likely be sufficient to motivate people to add meaning to their lives. Second, in a universe with preferences, we would not know what these preferences are based upon and whether they are trustworthy, as shown by the naturalistic version of the Euthyphro dilemma. Consequently, we would still be responsible for deciding how to live our lives.

There are some actions, however, that can help to relieve existential anguish, including letting go of the desire for the universe to take on the role of God in his absence, accepting the universe as "our home", and appreciating what the universe has to offer us.

\section{Acknowledgements}

Thanks to Stephen Leach and James Tartaglia for inviting me to contribute to this issue and for providing helpful comments.

\section{References}

Adams, R. (1987). The virtue of faith and other essays in philosophical theology. Oxford: Oxford University Press. 
Benatar, D. (2017). The human predicament: A candid guide to life's biggest questions. Oxford: Oxford University Press.

Camus, A. (1955). The myth of Sisyphus and other essays (J. O’Brien, trans.). New York: Vintage International.

Hansson, S. O. and Grüne-Yanoff, T. (Summer 2018 Edition), Preferences. In E. N. Zalta (Ed.), The Stanford Encyclopedia of Philosophy, https://plato.stanford.edu/archives/sum2018/entries/preferences/.

Landau, I. (2017). Finding meaning in an imperfect world. Oxford: Oxford University Press.

Lillehammer, H. (2017). The nature and ethics of indifference. The Journal of Ethics 21(1), 17-35.

Metz, T. (2009). Happiness and meaningfulness: some key differences. In L. Bortolotti (Ed.), Philosophy and Happiness (pp. 3-20), London: Palgrave-Macmillan.

Metz, T. (2013). Meaning in life: an analytic study. Oxford: Oxford University Press.

Russell, B. (2000). A free man's worship. In E. D. Klemke (Ed.), The meaning of life (pp. 71-77), Oxford: Oxford University Press.

Ryan, R. and Deci, E. (2000). "Intrinsic and extrinsic motivations: classic definitions and new directions." Contemporary Educational Psychology, 25(1), 54-67.

Sartre, J. (2007). Existentialism is a humanism (C. Macomber, trans.). New Haven: Yale University Press.

Trisel, B. A. (2015). Does death give meaning to life? The Journal of Philosophy of Life 5(2), 62-81. Trisel, B. A. (2019). How human life matters in the universe: a reply to David Benatar. The Journal of Philosophy of Life (9)1, 1-15.

Wielenberg, E. (2005). Value and virtue in a godless universe. Cambridge: Cambridge University Press. 
Brooke Alan Trisel

Email: triselba@cs.com 